\title{
A cobertura produzida pelo caderno de esporte da Folha de S.Paulo acerca da eliminação da seleção brasileira de futebol feminino na Copa do Mundo de 2015
}

\section{Coverage produced by the sports section of Folha de S.Paulo about elimination of the Brasilian women's national soccer team in the World Cup in 2015}

\author{
Bruno José Gabriel \\ Universidade Estadual de Ponta Grossa - UEPG - Ponta Grossa - Brasil \\ brunogabriel uepg@hotmail.com \\ Miguel Archanjo de Freitas Júnior \\ Universidade Estadual de Ponta Grossa - UEPG - Ponta Grossa - Brasil \\ mfreitasjr@uepg.br
}

\begin{abstract}
Resumo
O objetivo deste artigo foi verificar e analizar a cobertura produzida pelo caderno de esporte do jornal Folha de S.Paulo acerca da eliminação da seleção brasileira de futebol feminino na Copa do Mundo de 2015. Para tanto, optou-se pela utilização dos instrumentos metodológicos da Análise de Conteúdo, pois eles direcionam os pesquisadores na verificação e na análise dos diversos tipos de discursos, dentre eles o jornalístico. Diante do tratamento dos resultados, concluiu-se que a cobertura do jornal foi caracterizada pela construção de realidades ausentes de disposições preconceituosas. Ao contrario, nas suas abordagens preponderaram nas interfaces performativas da coletividade e da individualidade brasileiras.
\end{abstract}

Palavras-chave: futebol feminino, jornalismo, Folha de S.Paulo, gênero.

\section{Abstract}

The aim of this paper was to verify and analyze the coverage produced by the sports section of Folha de S.Paulo newspaper about elimination of the Brazilian women's national soccer team in the World Cup of 2015. To that end, was opted for the use of methodological instruments of the Content analysis, because they direct the researchers in the verification and in the analysis of the several types of discourses, among those, the ones found in newspapers. Through the treatment of the results, it was concluded that the newspaper coverage was characterized by the construction of absent realities of prejudices. On the contrary, in their approaches prevailed the performative interfaces of collectivity and individuality of Brazilian.

Keywords: women's soccer, journalism, Folha de S.Paulo, gender. 


\section{Introdução}

Há muitas temporalidades históricas o futebol é o esporte que detém o maior volume de capital simbólico ${ }^{1}$ dentre todos os que estão dispostos no campo esportivo brasileiro. Consequentemente, ele passou a estar presente no cotidiano dos milhões de habitantes brasileiros, por intermédio do que Guedes (1982) denominou de um sistema de criação e interpretação de símbolos e práticas associadas, o qual de modo algum está desarticulado de outros aspectos sociais e culturais. Essa situação é mais facilmente observada durante a participação da seleção nacional em uma Copa do Mundo, pois a rotina laboral e a arquitetura das cidades são significativamente alteradas. As empresas, as residências, as escolas, as universidades, os clubes, o comércio e todos os outros esportes praticamente param para torcer pelo Brasil, integrando o verde e o amarelo ao seu habitus cotidiano.

Neste momento, o futebol sobrepuja claramente os limites territoriais do campo de jogo mediante as tomadas de posição sobre ele realizadas. Dentre elas estão às coberturas jornalísticas, produções capazes de elaborar ou reforçar as realidades sociais desdobradas em afirmações, crenças, mitos, ideias, valores, significados e representações referentes e transcendentes ao subcampo futebolístico. Entretanto, ao observar a quantidade de publicações dos jornais impressos, torna-se evidente 0 contraste cultural adquirido pelo futebol quando acrescido do vocábulo "feminino". O futebol "feminino", exceto em algumas situações pontuais, como na disputa final do PanAmericano de 2007, Brasil versus Estados Unidos (EUA), assistida por aproximadamente oitenta mil torcedores, não dispõe da mesma significância cultural que 0 masculino. Assim, acaba obtendo pouca ou nenhuma visibilidade nesses veículos de comunicação.

Ao tratar dessa temática, Moura (2003), Mourão e Morel (2005) e Gabriel (2015) demonstraram que os jornais impressos têm produzido coberturas efêmeras acerca do futebol feminino desde as décadas iniciais do século XX. Os autores também salientaram que os conteúdos discursivos das publicações foram preconceituosos em alguns momentos, objetivando contribuir com o habitus individual e social requisitantes do impedimento ou da adaptação da mulher em relação à prática do futebol.

Diante desta problematização, o presente artigo objetivou verificar e analisar a cobertura produzida pelo caderno de esporte do jornal Folha de S.Paulo acerca da eliminação da seleção brasileira de futebol feminino na Copa do Mundo em 2015. A realização desta pesquisa justifica-se, pois na sociedade brasileira contemporânea os discursos de alguns veículos impressos continuam dispondo de uma influência bastante grande na estruturação e reestruturação de habitus individuais e sociais generificados. Habitus generificados estes, que, em seus desdobramentos práticos, podem ou não dificultar à inserção e a manutenção das mulheres no futebol e no subcampo futebolístico feminino.

\section{Metodologia}

Para alcançar o objetivo desta pesquisa, indicado na sessão introdutória, optou-se pela utilização dos instrumentos metodológicos da Análise de Conteúdo (AC), pois eles direcionam os pesquisadores na análise dos diversos tipos de discursos existentes, dentre eles o jornalístico. Bardin (2011) a definiu como um conjunto de instrumentos metodológicos de análise das comunicações, que visa obter, por intermédio de procedimentos sistemáticos e objetivos de descrição do conteúdo das mensagens, indicadores (quantitativos ou não) permissíveis de inferências sobre os conhecimentos

\footnotetext{
${ }^{1}$ O capital simbólico pode ser definido como uma medida do reconhecimento, da significância, do prestígio e/ou do carisma disposto por um agente (indivíduo ou instituição) num determinado campo. Cf. BOURDIEU, Pierre. O poder simbólico. 6. ed. Rio de Janeiro: Bertand Brasil, 2003.
} 
relativos às condições de produção/recepção destas. $O$ fator comum destes instrumentos múltiplos e multiplicados é uma hermenêutica controlada, baseada na dedução, a inferência.

Nesse sentido, aplicaram-se os instrumentos referentes às diferentes etapas que constituem a organização analítica da $\mathrm{AC}$, a qual está estruturada em torno de três polos cronológicos. São eles, a pré-análise, a exploração do material e os tratamentos dos resultados, as inferências e as interpretações.

Durante a pré-análise, etapa correspondente à organização propriamente dita do material empírico, foram realizadas as três missões necessárias, que não são sucedidas, obrigatoriamente, segundo uma ordem cronológica. Quais sejam, a escolha dos documentos a serem analisados, a indicação do(s) objetivo(s) e da(s) hipótese(s) e a eleição dos índices e dos indicadores que fundamentam a análise final.

Todas as decisões supracitadas resultaram da realização dos procedimentos das cinco subetapas da pré-análise. Iniciou-se pela primeira, denominada de leitura flutuante. Ao objetivar a verificação e a análise da cobertura jornalística produzida acerca da seleção brasileira de futebol feminino, escolheu-se o dispositivo impresso como o material analítco. Esta ramificação dos veículos de comunicação foi escolhida, pois mesmo com a emergência de outras, como a televisão, o rádio e a internet, ela ainda continua dispondo de uma influência bastante grande na internalização das disposições dos acontecimentos nos habitus individuais e sociais dos brasileiros. (PONTES; SILVA, 2012).

Dentre os jornais estruturados no subcampo jornalístico impresso, definiu-se apenas a Folha de S.Paulo como documento empírico por dois motivos interdependentes. O primeiro refere-se ao volume de capital simbólico que ela acumulou nas conjunturas precedentes, resultando na sua disposição em um dos veículos comunicativos diários de abrangência nacional mais influente na sociedade brasileira contemporânea. ${ }^{2} \mathrm{O}$ Segundo, mas não menos importante, refere-se às particularidades editoriais, crítica, pluralista, apartidária e moderna ${ }^{3}$ que distingue a produção de sentidos das coberturas dos seus cadernos temáticos em relação aos dos outros jornais. (FOLHA DE S.PAULO, 2013).

O contato inicial com os textos do jornal ocorreu por intermédio do seu acervo virtual, ${ }^{4}$ que disponibiliza as versões impressas de maneira digitalizada. A sua leitura na íntegra direcionou a realização da próxima subetapa, denominada de escolha dos documentos. E, a partir desta, definiu-se o corpus da pesquisa.

Diante das impressões emergidas durante a leitura flutuante, e do conhecimento das lógicas de funcionamento específicas dos diferentes cadernos temáticos constituintes da Folha de S.Paulo (documento escolhido), definiu-se que o corpus da pesquisa seria as matérias (colunas, entrevistas, notas, notícias e reportagens) publicadas no seu caderno

\footnotetext{
${ }^{2}$ A influência da Folha de S.Paulo pode ser observada em diversos momentos, dentre eles vale referenciar a utilização das suas matérias por outros veículos de comunicação na abordagem de qualquer temática, algo bastante recorrente, sobretudo nos jornais televisivos, e por meio do índice de circulação. Aliás, ela foi o jornal diário mais lido, em 2015, no Brasil. Segundo o Instituto Verificador de Circulação (IVC), somados impresso e digital, o veículo teve circulação média de 355,9 mil exemplares. Cf. IVC. Disponível em: http://ivcbrasil.org.br/default.asp?85728. Acesso em: 18 jul. 2016.
}

3 O princípio editorial crítico designa que a Folha de S.Paulo constrói a realidade de um ponto de vista crítico, comparando fatos, estabelecendo analogias, identificando atitudes contraditórias e veiculando diferentes versões sobre o mesmo acontecimento. $O$ pluralista designa que as múltiplas interpretações provenientes de uma sociedade complexa devem ser publicadas no jornal. $\mathrm{O}$ apartidário designa que 0 jornal não se atrela a grupo, tendência ideológica ou partido político e procura adotar posição clara em toda questão controversa. Mesmo quando defende tese, ideia ou atitude, não deixa de noticiar e publicar posições divergentes das suas. O moderno designa a introdução na discussão pública de temas que não tinham ingressado nela, de novos enfoques, preocupações e tendências. Cf. FOLHA DE S.PAULO. Manual da redação. 19 ed. São Paulo: Publifolha, 2013.

${ }^{4}$ Cf. ACERVO. Disponível em: http://acervo.folha.uol.com.br/. Acesso em: 19 jul. 2016. 
de esporte, no dia 21 de junho de 2015, que abordaram ou mencionaram de alguma maneira a seleção feminina e as suas jogadoras.

A escolha desta baliza temporal justifica-se, pois corresponde ao período em que a eliminação da seleção feminina na principal competição futebolística, a Copa do Mundo, organizada pela Féderation Internacional de Football Association (FIFA), foi coberta. Já a opção pelo caderno de esporte do jornal deveu-se a dois motivos distintos, entretanto interdependentes. O primeiro foi à especificidade do seu conteúdo discursivo, nutrido pelo jornalismo esportivo. ${ }^{5} \mathrm{E}$ o segundo foi a sua representatividade perante o público leitor, sendo apontado pela própria Folha de S.Paulo como um dos cadernos mais lidos dentre os que a conformam.

Nesse sentido, a associação entre as compreensões e as impressões provenientes da leitura flutuante, da determinação do corpus, de uma revisão de literatura sobre a temática e dos resultados obtidos por uma dissertação que verificou e analisou o conteúdo discursivo da Folha de S.Paulo, entre 1991 e 2011, acerca da seleção feminina de futebol, ${ }^{6}$ possibilitou a formulação de uma (1) hipótese. Vejamos:

1H: Acredita-se que o conteúdo discursivo das matérias publicadas não esteja associado a interfaces do tipo fragilidade feminina, estética corporal (espetacularização e masculinização) em detrimento das relacionadas a performance da individualidade e da coletividade brasileiras.

Terminada as tarefas da "pré-análise", por intermédio da referência dos índices (temáticas) e dos indicadores (presença ou ausência) - quarta subetapa -, da coleta das matérias e da preparação do material empírico - quinta subetapa -, efetivaram-se as da etapa subsequente, denominada de "exploração do material". Elas correspondem às operações de codificação, desconto ou enumeração relacionadas às decisões anteriores. Por conseguinte, definiu-se que as unidades de registro (UR), recortes semânticos que direcionam a categorização, seriam as temáticas centrais emergentes das abordagens das publicações. E as unidades de contexto (UC), elementos que referenciam o local de emersão das UR, seriam os corpos das matérias em sua totalidade.

Definidas as UR e as UC, efetivou-se a contagem das UR (o que normalmente se conta) encontradas, embasada na regra de enumeração denominadas de "presença (ou ausência)", clarificando as suas visibilidades. Diante dessas definições, optou-se pela manutenção da designação da temática encontrada, múltiplas $(2)^{7}$, como o título geral da categoria nas quais as UR ficaram agrupadas.

$\mathrm{Na}$ sessão subsequente foi realizada a descrição e a análise textual das UC referente às UR agrupadas na categoria múltiplas, pois elas coadunam com o objetivo desta pesquisa. Por meio desta ação foi possível efetivar os tratamentos dos resultados, as inferências e as interpretações, últimas tarefas metodológicas da AC.

\footnotetext{
5 O jornalismo esportivo é estruturado com particularidades que o distingue de outros. Por exemplo, durante a produção dos seus discursos, a subjetividade do jornalista esportivo é menos regulada institucionalmente, tornando menos grave a demonstração do time do coração pelo profissional do esporte do que a preferência de um editor de política por um candidato ou partido. Cf. GASTALDO, É. L.; LEISTNER, R. "A mais gaúcha de todas as Copas": identidades brasileiras e imprensa esportiva na Copa do Mundo. Interin, Curitiba, v. 2, n. 2, p. 1-16, jan./jul. 2006.
}

${ }^{6}$ Cf. GABRIEL, B. J. A cobertura acerca da seleção brasileira de futebol feminino realizada pelo caderno de esporte da Folha de S.Paulo (1991-2011). 2015, 252 f. Dissertação (Mestrado em Ciências Sociais Aplicadas) - Universidade Estadual de Ponta Grossa, Ponta Grossa, 2015.

7 Consideramos que a temática emergente de uma matéria receberia a designação nominal "múltipla(s)" quando emergisse dois ou mais temas centrais do mesmo texto. 


\section{Resultados e discussão}

Antes de efetivar o tratamento dos resultados, as inferências e as interpretações, buscou-se compreender algumas características do campo e da produção jornalística, embasando-se no referencial teórico dos campos de Pierre Bourdieu e seus afins, como Nelson Traquina. Os pressupostos dessa teoria coadunam com os metodológicos da AC, pois também externalizam contrariedade à ilusão da transparência dos fatos, a compreensão espontânea dos fenômenos da sociedade, a evidência do saber subjetivo, a intuição em proveito do construído e a sociologia ingênua.

O campo jornalístico, tal como propõem os pressupostos teóricos de Bourdieu (1983), se apresenta a apreensão sincrônica como um espaço estruturado de posições (ou postos) cujas propriedades dependem das suas distintas posições nessa estrutura, podendo ser analisadas independentemente das características de seus ocupantes (em parte determinadas por eles). Assim como os outros campos, o jornalístico extrema-se pelo confronto entre agentes inseridos na estrutura, disputando um objeto, maior média de circulação e/ou influência social, dentre outros existentes, que estão aptos para tal ocorrência e dotados de habitus que implique no conhecimento e no reconhecimento das leis imanentes da disputa.

Segundo Bourdieu (1983, p. 94), habitus corresponde aos "sistemas de disposições" adquiridas pelas aprendizagens (implícitas ou explícitas) que funcionam como "sistemas de esquemas geradores", gerando estratégias que podem ser objetivamente afins aos interesses objetivos de seus autores sem terem sido concebidas para este fim. Vale ressaltar, que os habitus dos ocupantes das posições jornalísticas são estruturados com "generalidades" do campo e com "especificidades" da sua posição nesse espaço, como, por exemplo, a ética "requisitada" na produção de qualquer tipo de jornalismo e a conformação deste a uma política editorial.

Mas, o que se entende por jornalismo, produto objetivado no campo jornalístico? Traquina (2005, p. 19/20, grifo nosso) formulou uma resposta para esta indagação, fragmentando-a em duas partes distintas, a primeira embasada em representações poéticas e a segunda nos pressupostos ideológicos dos jornalistas, entretanto interdependentes. Vejamos:

Poeticamente pode-se dizer que jornalismo é a vida, tal como é contada nas notícias de nascimentos e de mortes, tal como o nascimento do primeiro filho de uma cantora famosa ou a morte de um sociólogo conhecido mundialmente. É a vida em todas as suas dimensões, como uma enciclopédia. Uma breve passagem pelos jornais diários vê a vida dividida em seções que vão da sociedade, a economia, a ciência e o ambiente, à educação, à cultura, à arte, [ao esporte], aos livros, aos media, à televisão, cobre o planeta com a divisão do mundo em local, regional, nacional (onde está essencialmente a política do país) e internacional. Um exame da maioria dos livros e manuais sobre jornalismo define as notícias em última análise como tudo o que é importante e/ou interessante. Isto inclui praticamente a vida, o mundo e o outer limits.

Os jornalistas responderiam prontamente, como define a ideologia profissional desta comunidade, que o jornalismo é a realidade. Há verdade nesta afirmação. Existe um acordo tácito entre os que escolhem essa profissão de jornalista e o leitor/ouvinte/telespectador que torna possível dar credibilidade ao jornalismo: o principal produto do jornalismo contemporâneo, a notícia, não é ficção, isto é, os acontecimentos ou personagens das notícias não são invenção dos jornalistas [...] dever-se-ia acrescentar rapidamente que muitas vezes essa "realidade" é contada como uma telenovela, e aparece quase sempre em pedaços, em acontecimentos, uma avalanche de acontecimentos perante a qual os jornalistas sentem como primeira obrigação dar resposta com notícias, rigorosas e se possível confirmadas, o mais rapidamente possível, perante a tirania do fator tempo. 
Na sequência, o autor ainda argumentou que o jornalismo é condicionado pelas diversas especificidades do seu processo produtivo, como a cultura da sociedade transversal ao jornalista e as posições político/editoriais do veículo de comunicação no qual ele exerce a sua profissão. Esse argumento é compatível com as ideias provenientes das teorias do jornalismo e da comunicação que defendem que ele não é apenas um transmissor de realidades, mas, em complemento a essa função, um produtor de sentidos. Assim, o jornalismo atuaria sobre a realidade, construindo coberturas específicas em função das especificidades do seu produtor.

Borelli (2001) também corrobora com esta proposição, salientando que os veículos de comunicação podem construir os acontecimentos sociais. Construção esta, que ao apreender $e$ interpretar $o$ acontecimento mobilizando rituais singulares acaba impregnando-o com os sentidos desejados. Por conseguinte, essa autora valida à proposição de que as coberturas jornalísticas podem construir múltiplos acontecimentos (realidades) a partir de um fato único.

Alsina (1989) coaduna com essa linha teórica, salientando que o mass media tornou-se um dos principais instrumentos de construção social da realidade. ${ }^{8}$ Segundo o autor, as coberturas dos jornais não se limitam a mediar às realidades para o público, pois atuam sobre elas, direcionando-as ao fim objetivado, realizando ações, omissões, falas e silêncios conscientes ou inconscientes.

Nesse sentido, Bourdieu (1996) afirmou que o discurso dos agentes sociais (indivíduo ou instituição) dispõe de poder instituidor de realidades, e, por conseguinte, influenciador na possível internalização das suas disposições, quando, embasadas no capital simbólico do discursista, as pessoas atribuem credibilidade a ele, autorizando-o na efetivação dos efeitos supracitados. Segundo Gastaldo (2000; 2003), o poder mencionado está localizado, na contemporaneidade brasileira, em grande parte, nos discursos produzidos pelas coberturas jornalísticas.

Desta forma, é possível afirmar que o discurso de alguns jornais dispõe da capacidade de influenciar na estruturação e reestruturação de habitus individuais e sociais generificados, os quais se encontram subjacentes às percepções (as maneiras como uma situação é visualizada), as apropriações (como elas são julgadas) e as ações (as diversas maneiras de agir em função das experiências armazenadas) da individualidade e da coletividade. Segundo Scott (1995), o gênero é elemento constitutivo das relações sociais baseadas nas diferenças percebidas entre os sexos, e uma forma primária de dar significado as relações de poder. Nesse contexto, o gênero tem sido utilizado também como alusão às construções sociais e culturais alicerçadas nos caracteres biológicos distintivos dos humanos. Assim, ao internalizarem os seus produtos, em maior ou menor escala, as pessoas acabam estruturando e reestruturando habitus masculino e feminino. Por sua vez, os seus desdobramentos práticos podem ou não dificultar à inserção e a manutenção das mulheres no futebol e no subcampo futebolístico feminino.

Com base nos argumentos supracitados, torna-se relevante verificar e analisar a cobertura produzida pelo caderno de esporte da Folha de S.Paulo acerca da eliminação da seleção brasileira de futebol feminino na Copa do Mundo em 2015. Antes de avançar, vale destacar que esse dispositivo impresso está alocado entre os dominantes do campo jornalístico desde a década de 1980.

O Brasil venceu os três adversários da fase inicial da competição, a Coreia do Sul $(2 \times 0)$, Espanha $(1 \times 0)$ e a Costa Rica $(1 \times 0)$, respectivamente. Encerrada a disputa contra as costarriquenhas, as australianas foram concretizadas como as próximas

8 Com base na bibliografia apresentada nas pesquisas que problematizaram o jornalismo, Berger e Luckmann (2004) são as principais referências no tocante ao conceito e as ramificações da realidade social. Segundo esses autores, a realidade social corresponde à qualidade que estrutura os fenômenos que as pessoas reconhecem ter um "ser" independente das suas volições. Cf. BERGE, P. L.; LUCKMAN, T. 2. ed. A construção social da realidade. Lisboa: Dinalivro, 2004. 
adversárias das brasileiras. Nos dias que antecederam a disputa, nenhuma matéria foi publicada acerca da temática. No entanto, após a derrota $(0 \times 1)$ e a conseguinte eliminação da Copa do Mundo, duas publicações construíram a respectiva realidade de maneiras distintas. Vejamos:

\footnotetext{
De freguês a algoz

A seleção brasileira, liderada por Marta, eleita cinco vezes pela FIFA a melhor jogadora do mundo, chegou ao duelo com amplo favoritismo.

O time australiano era o maior freguês brasileiro em partidas válidas por Copas do Mundo e Jogos Olímpicos [...]

Além do retrospecto positivo, o time do técnico Oswaldo Alvarez, o Vadão, fez a melhor campanha da primeira fase do Mundial, com três vitórias e sem levar um gol.

Porém, quando a bola rolou neste domingo, o que se viu foi muito equilíbrio entre as duas seleções [...]

Quando a partida já caminhava para a prorrogação, a Austrália se aproveitou da falha da goleira Luciana para fazer o gol do triunfo. (FOLHA DE S PAULO, 2015, p. B2).
}

Alicerçado no desempenho durante a competição e no retrospecto histórico dos enfrentamentos entre brasileiras versus australianas em Copas do Mundo e Jogos Olímpicos, foi ressaltado que o "amplo favoritismo" do Brasil, ausente dos noticiários antes da disputa, não foi efetivado. Por conseguinte, a partida foi marcada pelo equilíbrio técnico e tático. Mas, embasado na última frase desse trecho em associação com o título da matéria em questão, "Goleira falha, e Brasil está fora da Copa", infere-se que, mesmo inexistindo manifestações efusivas que relativizassem a objetividade da produção jornalística, houve o apontamento de uma culpada pela derrota, e, conseguintemente, pela eliminação da seleção brasileira da Copa do Mundo. Qual seja a goleira Luciana.

Segundo Helal (1998), o apontamento de elementos justificadores não relacionados à superioridade técnica e tática dos adversários é algo bastante antigo e recorrente nas coberturas produzidas pelo jornalismo esportivo brasileiro após as eliminações masculinas em Mundiais. No entanto, tal como constatou Gabriel (2015), é muito recente e incomum referente à seleção feminina.

Freitas Jr. (2009, 2012) além de corroborar com Helal (1998), denominou essa prática de "cultura da desculpa", teia materializada pelo habitus dos profissionais da imprensa ao longo da história das Copas do Mundo masculinas, que tenta justificar ou explicar as diversas eliminações futebolísticas brasileiras. Ao que parece tal prática parece ter sido transposta para a cobertura jornalística esportiva feminina da Folha de S.Paulo, pois em algumas eliminações precedentes a atual, como, por exemplo, na de 2011, também houve o apontamento de discurso(s) explicativo(s) ou justificativo(s). Apontamentos estes, que, conforme detectou Costa (2008), tem a figura da individualidade ou da coletividade de jogadores enquanto uma das possibilidades precípuas para atribuir a culpa.

A outra matéria que abordou a eliminação brasileira construiu uma realidade distinta da anterior para o acontecimento. Abaixo do subtítulo "azares", Kfouri (2015, p. B3) discursou o seguinte:

Tanto a seleção brasileira sub-20 jogou para ser campeã mundial, na Nova Zelândia, quanto a feminina mereceu ir adiante na Copa do Mundo, no Canadá. Mas a bola pune os gols perdidos contra a Sérvia e Austrália, respectivamente, castigaram os meninos e as mulheres.

Verdade que, nas quartas de final, no sub-20, contra Portugal, nossos meninos foram massacrados e só se classificaram nos pênaltis porque, naquele dia, os deuses dos estádios estavam bravos com os lusitanos. 
Para o articulista, a seleção feminina mereceu ir adiante na competição. No entanto, dois aspectos, o azar e os deuses futebolísticos, materializaram uma punição/castigo para as brasileiras. Qual seja a eliminação precoce diante das australianas. Aqui, a explicação ou a justificativa para a ocorrência dessa situação não está alicerçada na figura de uma jogadora, mas sim em alguns dos elementos estruturantes da superstição.

Mas, o que é superstição, algo bastante presente na inter-relação cultural brasileira, futebolística e jornalística? Segundo Daolio (2005), ela é um elemento simbólico manifesto no habitus dos agentes sociais, colocado em prática pela intenção ou atribuição de "sorte" ou "azar" para algumas situações. O autor ainda salientou que os aspectos mencionados estão calçados em uma visão de mundo crente de que a ordem pode ser explicada por meio dos fenômenos sobrenaturais.

\section{Conclusão}

Diante do tratamento dos resultados, concluiu-se que a cobertura produzida pelo caderno de esporte da Folha de S.Paulo acerca da eliminação da seleção brasileira de futebol feminino na Copa do Mundo de 2015 foi caracterizada pela construção de realidades ausentes de disposições preconceituosas. Ao contrário, nas suas abordagens preponderam nas interfaces performativas da coletividade e da individualidade brasileiras, aproximando-se das coberturas futebolísticas do gênero masculino, confirmando a hipótese elencada nesta pesquisa.

Essa constatação é muito importante, pois em função do capital simbólico que a Folha de S.Paulo dispõe na sociedade brasileira contemporânea, pode-se afirmar que jornal está contribuindo positivamente na estruturação e reestruturação de habitus individuais e sociais ausentes de generificações distintivas. Habitus estes, que, em seus diversos desdobramentos práticos, podem contribuir positivamente na reverberação de atividades apropriadas aos humanos em sua totalidade e não exclusivamente a um ou outro gênero humano. $E$, por conseguinte, na inserção e na manutenção das mulheres no futebol e no subcampo futebolístico feminino.

\section{Referências}

ALSINA, M. R. La construcción de la noticia. Buenos Aires: Paidós, 1989.

BARDIN, L. Análise de conteúdo. Lisboa: Edições 70, 2011.

BORELLI, V. Cobertura midiática de acontecimentos esportivos: uma breve revisão de estudos. In: INTERCOM, 24., 2001, Campo Grande. Anais... Campo Grande: [s. n.], 2001. p. 1-15.

BOURDIEU, P. Algumas propriedades dos campos. In. Rio de Janeiro: Marco Zero, 1983, p. 89-94.

Questões de sociologia.

A economia das trocas lingüísticas: o que falar quer dizer. São Paulo: Edusp, 1996.

COSTA, L. M. A trajetória da queda: as narrativas da derrota e os principais vilões da seleção brasileira em Copas do Mundo. 2008. 159 f. Tese (Doutorado em Letras) Programa de Pós-Graduação em Letras, Universidade do Estado do Rio de Janeiro, Rio de Janeiro. 
DAOLIO, J. A superstição no futebol brasileiro. In: . Futebol, cultura e sociedade. Campinas: Autores Associados, 2005. p. 3-19.

FOLHA DE S.PAULO. Manual de Redação. São Paulo: Publifolha, 2013.

FOLHA DE S.PAULO. Goleira falha, e Brasil está fora da Copa. São Paulo: Caderno de Esporte, 2015. p. B2.

FREITAS JR., M. A. de. No meio do caminho: tensões presentes nas representações sobre o futebol e o ideal de modernidade brasileira na década de 1950. 2009, 320 f. Tese (Doutorado em História) - Programa de Pós-graduação em História, Universidade Federal do Paraná, Curitiba.

. Copa do Mundo de 1950: a cultura da desculpa como justificativa de um fracasso. In: __ _ CAPRARO, André Mendes. (Org.). Passe de letra: crônica esportiva e sociedade brasileira. Ponta Grossa: Vila Velha, 2012. p. 118-147.

GABRIEL, B. J. A cobertura acerca da seleção brasileira de futebol feminino realizada pelo caderno de esporte da Folha de S.Paulo (1991-2011). 2015, 252 f. Dissertação (Mestrado em Ciências Sociais Aplicadas) - Programa de pós-graduação em ciências sociais aplicadas, Universidade Estadual de Ponta Grossa, Ponta Grossa.

GASTALDO, É. L. "Os campeões do século": nota sobre a definição da realidade no futebol espetáculo. Revista Brasileira de Ciências do Esporte, Florianópolis, v. 22, n. 1, p. 105-124, set. 2000 .

Futebol, mídia e sociedade no Brasil: reflexões a partir de um jogo. Caderno IHU Idéias, São Leopoldo. v. 1, n. 10, p. 1-28. 2003.

.; LEISTNER, R. "A mais gaúcha de todas as Copas": identidades brasileiras e imprensa esportiva na Copa do Mundo. Interin, Curitiba, v. 2, n. 2, p. 1-16, jan./jul. 2006.

GUEDES, S. L. Subúrbio: celeiro de craque. In: DAMATTA, R. (Org.). Universo do futebol: esporte e sociedade brasileira. Rio de Janeiro: Pinakotheke, 1982. cap. 3. p. 5974.

HELAL, R. Mídia, construção da derrota e o mito do herói. Motus Corporis, Rio de Janeiro, v. 5, n. 2, p. 141-155, 1998.

KFOURI, J. Vexame afastado. Folha de S.Paulo, São Paulo, 17 jun. 2015. Caderno de Esporte. p. B9.

MOURA, E. As relações entre lazer, futebol e gênero. 2003, 112 f. Dissertação (Mestrado em Educação Física) - Programa de pós-graduação em Educação Física, Universidade Estadual de Campinas, Campinas.

MOURÃO, L.; MOREL, M. As narrativas sobre o futebol feminino: o discurso da mídia impressa em campo. Revista Brasileira de Ciências do Esporte, Campinas, v. 26, n. 2, p. 73-86, jan. 2005.

PONTES, F. S.; SILVA, G. Mídia noticiosa como material de pesquisa: recursos para o estudo de produtos jornalísticos. In: BOURGUGNON, J. A.; OLIVEIRA JUNIOR, C. R. de. 
(Orgs.). Pesquisa em ciências sociais: interface, debates e metodologias. Ponta Grossa: Todapalavra, 2012. p. 29-77.

SCOTT, J. W. Gênero: uma categoria útil de análise histórica. Educação e Realidade, Porto Alegre, v. 10, n. 2, p. 71-99, jul./dez. 1995.

TRAQUINA, N. Teorias do jornalismo, porque as notícias são como são. 2. ed. Florianópolis: Insular, 2005. 